\title{
Nobel reactions
}

\author{
The Nobel Prize, for all its shortcomings and imperfections, remains unmatched when it comes to the \\ kind of emotions it generates.
}

As Nature Physics went to press, the 2017 Nobel Prizes were yet to be announced. We did place our bets, of course, curious which physicists would be 'the ones' this year. But independently of who will have ended up with a ticket to Stockholm, already before the announcement it was clear that, for the new physics laureates, 3 October 2017 would become essentially the first day of the rest of their lives. And the disruption will equally affect their wider private and professional environments.

Reservations about the role the Nobel Prize has in science and the procedures of how it is awarded are well documented (see, for example, the Commentary by Shivaji Sondhi and Steven Kivelson in last month's issue $\left.^{1}\right)$. There are science prizes with larger purses - a Breakthrough Prize is worth three times more than a Nobel Prize; awards with longer histories - the Copley Medal of the Royal Society has been awarded since 1731, 170 years longer than the Nobel Prize; and formats that may be more adapted to the practices of modern science. Nevertheless, the standing of the Nobel Prize in the scientific reward system, and in society at large, remains unique. The impact of 'who got it' ripples through space and time more than for any other science award.

\section{For the new physics laureates, 3 October 2017 is essentially the first day of the rest of their lives.}

The immediate reaction is typically intense already. Richard Feynman, as was his wont, found eminently citable words to describe what happened when the Nobel committee announced the 1965 Prize in Physics, which he shared with Sin-Itiro Tomonaga and Julian Schwinger. The award, Feynman said in his Nobel banquet speech, elicited many reactions: "of fathers turning excitedly with newspapers in hand to wives; of daughters running up and down the apartment house ringing neighbours' doorbells with news; victorious cries of 'I told you so' by those having no technical knowledge - their successful prediction being based on faith alone; from friends, from relatives,

from students, from former teachers, from scientific colleagues, from total strangers". In the many messages received, Feynman saw two common elements: joy and affection. "The prize was a signal to permit them to express, and me to learn about, their feelings."

But beyond such positive expressions of interest, other sentiments, and sensitivities, will surface equally quickly. Harald zur Hausen, one of the recipients of the 2008 Nobel Prize in Physiology or Medicine, recalled in his own Nobel banquet speech the reaction of his three-year-old granddaughter, who on hearing the news burst into tears - telling her parents that she too wants a Nobel Prize. That sort of reaction, zur Hausen continued, might have been rather representative: "When I told this to one of my colleagues, his face became thoughtful and he then stated: 'Your granddaughter expressed the desire of a multitude of scientists, except that they usually don't cry in public and are reluctant to talk about it."

And then there is the public spotlight that the Nobel Prize brings like no other science award. "We have gone from zero to the condition of movie stars", André Lwoff, one of the 1965 laureates in Physiology or Medicine, once said about himself and his collaborators. The American sociologist Harriet Zuckerman compared the issues some laureates had when coping with celebrity status with "the disruptive consequences of abrupt upward social mobility"2. In her 1967 analysis of 71 American science Nobel laureates ${ }^{3}$, based on interviews with them, Zuckerman observed a measurable decrease in productivity following the award - even if the Nobel Price was originally conceived as a stimulus to further achievement especially for laureates whose standing increased substantially, compared to those who had already been members of the 'scientific elite' before receiving Nobel honours. Also pronounced was the desire of academic institutions to stress laureates affiliations with them, remote as they may have been. And Zuckerman found evidence that many laureates erected barriers between themselves and their colleagues, leading, for example, to a faster breakup of existing collaborations, unless they were between co-laureates.

Such tendencies are unlikely to have changed much in the decades since Zuckerman's study. If anything, the trend towards larger collaborations - such as, say, LIGO - might make discussions more likely of why one to three of the many scientists involved have to be singled out. Today's even greater academic mobility gives even more institutions a perceived right to claim a share of the laureate, whether the latter wants it or not. And the pace of modern news cycles only accelerates the spread of any sentiment.

Still, that science evokes emotions on such a scale should also be something to marvel - especially if they are about joy and affection, as we largely saw last year when the Prize in Physics was awarded to David Thouless, Michael Kosterlitz and Duncan Haldane ${ }^{4}$. There is no denying that the Nobel Prize is special. So let watching the reactions pouring in be part of the experience of being a scientist.

\footnotetext{
References

1. Sondhi, S. \& Kivelson, S. Nat. Phys. 13, 822 (2017).

2. Zuckerman, H. Am. Sci. 66, 420-425 (1978).

3. Zuckerman, H. Sci. Am. 217, 25-33 (May, 1967).

4. Nat. Phys. 12, 987 (2016).
} 